University of South Carolina

Scholar Commons

2005

\title{
A Miniaturized Hilbert PIFA for Dual-Band Mobile Wireless Applications
}

Mohammed Z. Azad

Motorola, Inc., azad@motorola.com

Mohammod Ali

University of South Carolina - Columbia, alimo@engr.sc.edu

Follow this and additional works at: https://scholarcommons.sc.edu/elct_facpub

Part of the Electrical and Computer Engineering Commons

Publication Info

Published in IEEE Antennas and Wireless Propagation Letters, Volume 4, 2005, pages 59-62.

http://ieeexplore.ieee.org/xpl/Recentlssue.jsp?reload=true\&punumber=7727

(C) 2005 by IEEE

This Article is brought to you by the Electrical Engineering, Department of at Scholar Commons. It has been accepted for inclusion in Faculty Publications by an authorized administrator of Scholar Commons. For more information, please contact digres@mailbox.sc.edu. 


\title{
A Miniaturized Hilbert PIFA for Dual-Band Mobile Wireless Applications
}

\author{
Mohammed Z. Azad and Mohammod Ali, Senior Member, IEEE
}

\begin{abstract}
A miniaturized planar inverted-F antenna (PIFA) is proposed for dual-band mobile phone application in the 900- and 1900-MHz bands. By employing a Hilbert geometry, an overall size reduction of $50 \%$ was achieved compared to a conventional rectangular PIFA. The proposed antenna can be easily printed on the inside surface of the plastic housing of a mobile phone or other wireless device. An experimental prototype of this miniature antenna was fabricated on $0.125 \mathrm{~mm}$ thick Duroid 5880 substrate. Measured results demonstrate dual-band characteristics with good radiation patterns.
\end{abstract}

Index Terms-Antenna, Hilbert, miniature, planar inverted-F antenna (PIFA), wireless.

\section{INTRODUCTION}

W ITH the widespread proliferation of telecommunication technology, the need for small, internal, multiband antennas has increased greatly [1]-[6]. Lately the planar inverted-F antenna (PIFA) has gained much interest due to its lower profile, good bandwidth, and ease of fabrication [1]-[5]. However, a dual-band PIFA operating in the $900 / 1900 \mathrm{MHz}$ mobile telephone operating frequency bands can occupy substantial space in order to satisfy the bandwidth requirements (880-960 MHz for GSM and 1850-1990 MHz for PCS). Utilizing geometrical configurations, such as meander or double meander resulted in smaller antennas operating as monopoles in [6].

Lately significant efforts have been made to study and optimize antennas based on the Hilbert type curve [7]-[9]. The usefulness of a Hilbert wire antenna in order to lower the antenna resonant frequency has been studied in [7]. In [8] a parametric study was conducted on a matched Hilbert antenna to understand its bandwidth and cross-polarization level. A printed Hilbert antenna was proposed in [9] for operation in the UHF band.

In this paper we introduce a PIFA that consists of a Hilbert geometry that can support dual-band operations at 900 and $1900 \mathrm{MHz}$. Utilizing the Hilbert curve results in a significantly smaller antenna than its conventional counterpart. The proposed antenna occupies a volume of only $4.3 \mathrm{~cm}^{3}$ (40 $\mathrm{mm}$ by $10.65 \mathrm{~mm}$ by $10 \mathrm{~mm}$ ). In contrast, a conventional dual-band PIFA occupies a volume of $8.8 \mathrm{~cm}^{3}(40 \mathrm{~mm}$ by $22.18 \mathrm{~mm}$

Manuscript received September 7, 2004; revised December 1, 2004. This work was supported in part by the National Science Foundation (NSF) Career Award ECS-0237783.

The authors are with the Department of Electrical Engineering, University of South Carolina, Columbia, SC 29208 USA (e-mail: alimo@engr.sc.edu).

Digital Object Identifier 10.1109/LAWP.2005.844128

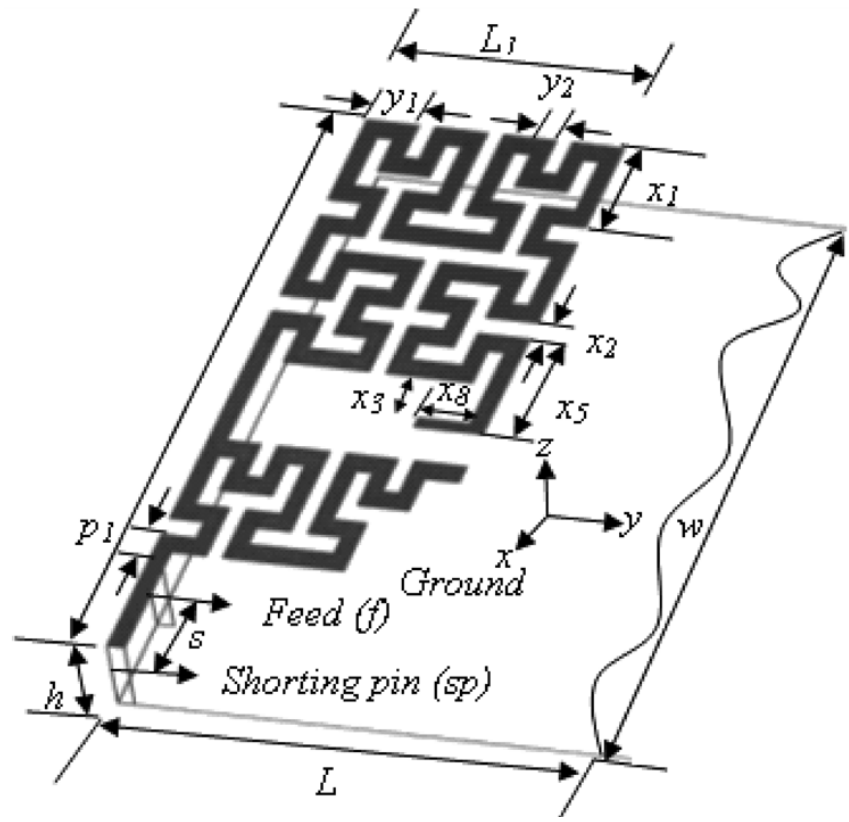

Fig. 1. Dual-band PIFA—Antenna A.

by $10 \mathrm{~mm}$ ). Thus, a $50 \%$ saving in antenna volume is readily achieved with our proposed design.

\section{ANTENNA DESIGN}

The antenna geometry conforming to the Hilbert profile effectively increases the length of the current flow path making it possible to develop a miniature antenna. Since to achieve dual-band performance at least two branches of a radiating element are needed [2], [5], we focus on studying antennas that contain two branches and are connected to each other near the feed [see Fig. 1]. For all antenna geometries, a ground plane made of a thin metallic conductor with length, $L=110 \mathrm{~mm}$ and width, $w=40 \mathrm{~mm}$ was considered. The antenna height was fixed at $10 \mathrm{~mm}$. Study and design of all antennas were conducted using Ansoft HFSS. First an antenna consisting of two Hilbert elements as shown in Fig. 1 was considered. The smaller element near the feedpoint is responsible for resonance in the high frequency band while the larger element is responsible for the resonance in the low frequency band. The models of each element were constructed following a higher order Hilbert curve as described in [8]. The individual segments and the trace width $(0.71 \mathrm{~mm})$ were selected such that the two elements can be accommodated within the width of the ground plane $(40 \mathrm{~mm})$. No 


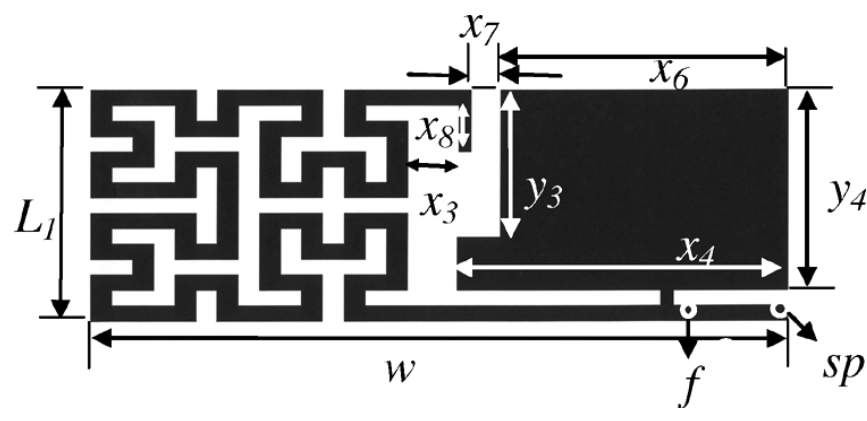

(a)

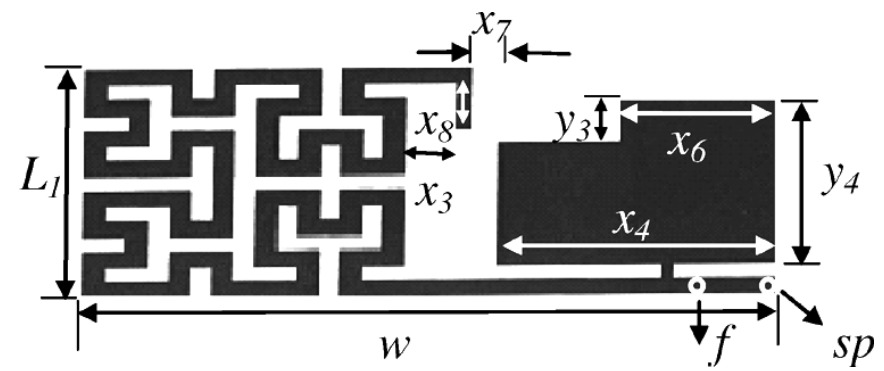

(b)

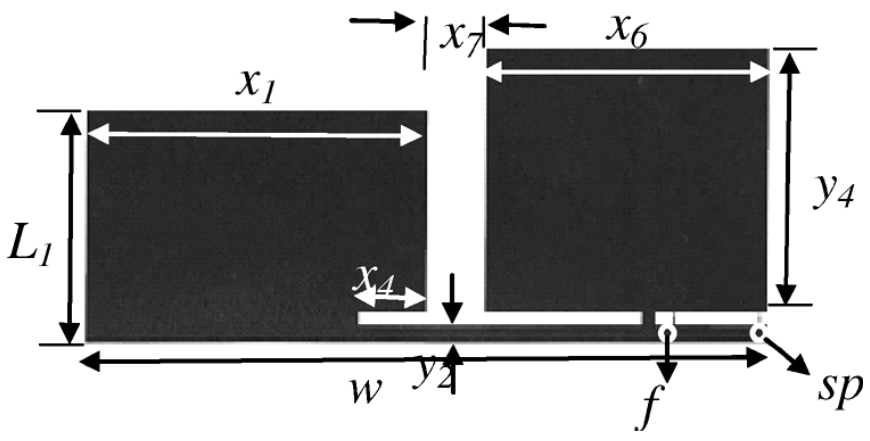

(c)

Fig. 2. (a) Antenna B. (b) Antenna C on 0.125-mm substrate. (c) Antenna D.

TABLE I

ANTENNA PARAMETERS

\begin{tabular}{c|c|c|c|c|c|c|c|c}
\hline & $x_{3}$ & $x_{4}$ & $x_{5}$ & $x_{6}$ & $x_{7}$ & $x_{8}$ & $y_{3}$ & $y_{4}$ \\
\hline $\mathrm{A}$ & 2.93 & --- & 7.3 & ---- & ---- & 1.13 & ---- & ---- \\
\hline $\mathrm{B}$ & 2.93 & 19 & --- & 16.5 & 1.68 & 2.13 & 7.08 & 9.23 \\
\hline $\mathrm{C}$ & 2.93 & 17.32 & --- & 7.47 & 0.86 & 0.71 & 1.08 & 7.82 \\
\hline
\end{tabular}

attempt was made to reduce the trace width and further miniaturize the antenna. We call this first model antenna A. All parameters for this antenna are listed in Table I.

Antenna A resonated at around 920 and $1920 \mathrm{MHz}$ and had good operating bandwidth in the low frequency band. In the high frequency band the bandwidth was relatively narrow. This prompted us to investigate a hybrid geometry consisting of a Hilbert element for the low frequency band and a plate element for the high frequency band. This resulted in the development of antenna B [Fig. 2(a)]. Both antennas, A and B were studied in the absence of any dielectric material.

To fabricate and measure the proposed antenna we considered to use a thin $(0.125 \mathrm{~mm}$ thickness $)$ Duroid $5880\left(\varepsilon_{\mathrm{r}}=2.2\right)$ substrate. A prototype antenna similar to antenna B was first modeled and simulated on Duroid 5880. A slight modification in the geometry of antenna B was required which resulted in antenna C. Thus, antenna $\mathrm{C}$ represents the design on $0.125 \mathrm{~mm}$ thick Duroid 5880 [Fig. 2(b)]. For comparison, a conventional PIFA was also modeled (Antenna D, Fig. 2(c)]. The parameters of the conventional antenna were: $w=40 \mathrm{~mm}, L_{1}=18.65 \mathrm{~mm}$, $x_{1}=20 \mathrm{~mm}, x_{4}=4 \mathrm{~mm}, x_{6}=16.47 \mathrm{~mm}, x_{7}=3.53 \mathrm{~mm}$, $y_{2}=0.71 \mathrm{~mm}, y_{4}=20.76 \mathrm{~mm}$, and $s=6 \mathrm{~mm}$ (distance between feed and shorting pin).

\section{RESULTS}

Computed VSWR and impedance data for antennas A and B are shown in Figs. 3 and 4, respectively. Measured VSWR data are shown in Fig. 5 for antenna C. The Hilbert geometry for antenna A was created and adjusted several times to achieve resonance at around 900 and $1900 \mathrm{MHz}$.

Similar adjustments in the geometrical parameters were also made for antennas B, C, and D. All antenna parameters are listed in Table I. From the VSWR plots of Fig. 3 it is clear that the bandwidths of antenna A are $9.4 \%$ and $4.4 \%$ within $2.5: 1$ VSWR. The bandwidth in the high frequency band for this configuration is relatively narrow for the 1900-MHz band PCS application. The bandwidths of antenna B are $10.4 \%$ and $7.3 \%$, respectively. Computed input impedance data for antennas A and $\mathrm{B}$ are shown plotted in Fig. 4. Clearly, the impedances at 1850 and $1990 \mathrm{MHz}$ for antenna A are much more spread than antenna B. Thus, even though all antennas are fairly well matched at their center frequencies antenna $\mathrm{A}$ is narrowband at the high frequency.

Similarly, computed bandwidths for antennas A, B, and C are shown in Fig. 5. Measured data for antenna $\mathrm{C}$ along with an inset photograph of the fabricated antenna are also shown in Fig. 5. Computed bandwidths for antenna $\mathrm{C}$ are $9.6 \%$ and $6.5 \%$, respectively while measured bandwidths are $8 \%$ and $5.6 \%$, respectively. The measured bandwidth is slightly narrower than the computed, particularly due to the high inductance provided by the center conductor of the coaxial feed line. In practical applications, metal strip type feed, as indicated in Figs. 1 and 2, is generally used which should improve the bandwidth further. 


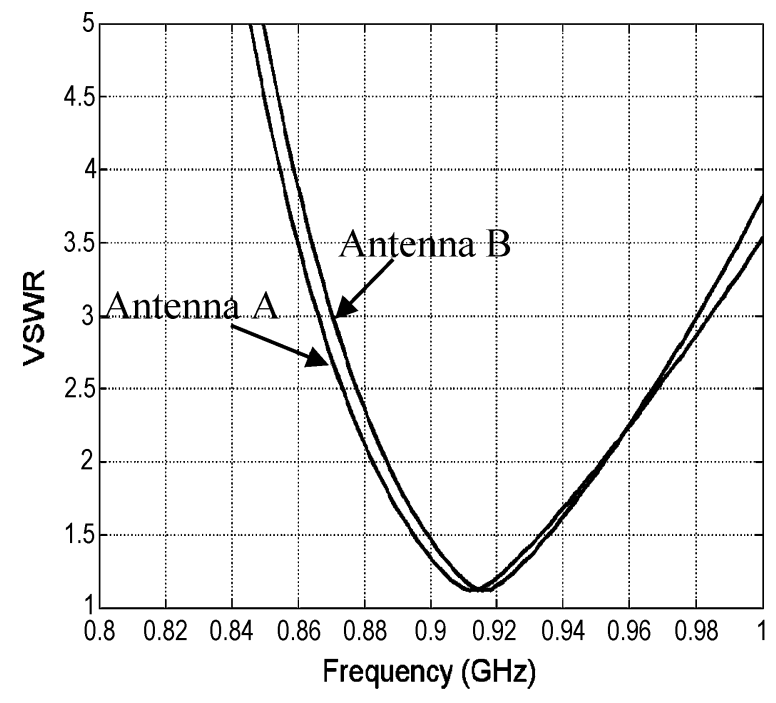

(a)

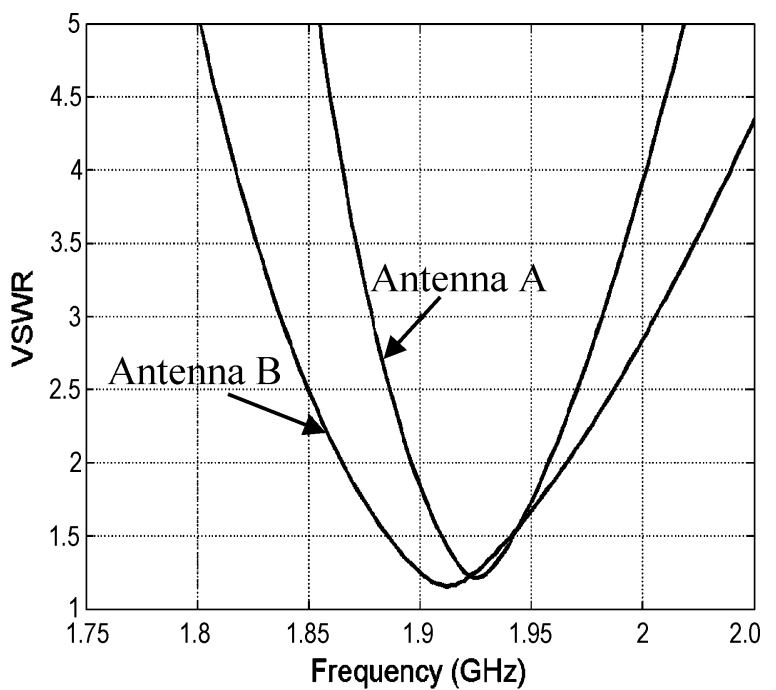

(b)

Fig. 3. Computed VSWR data for antennas A and B near (a) 900-MHz band and (b) 1900-MHz band.

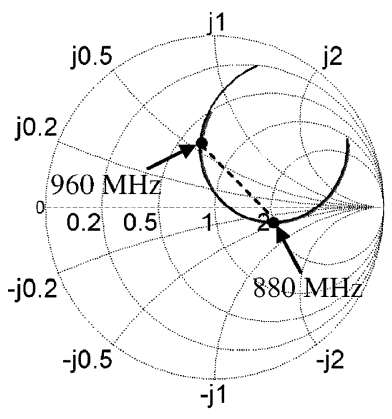

(a)

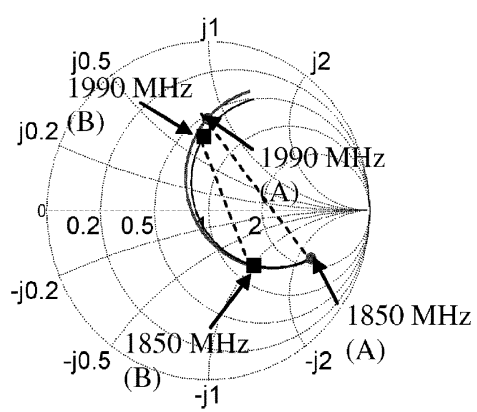

(b)
Fig. 4. Computed input impedance data for antennas A and B near (a) 900-MHz band and (b) 1900-MHz band.

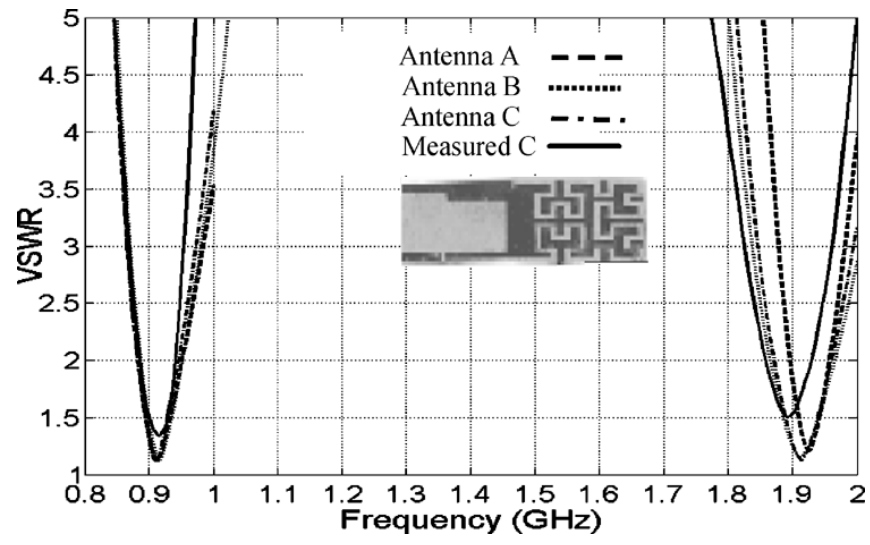

Fig. 5. Computed and measured VSWR characteristics of antennas A, B, and $\mathrm{C}$.

Computed current distributions of antenna $\mathrm{C}$ at $910 \mathrm{MHz}$ and $1912 \mathrm{MHz}$ are shown in Fig. 6. As apparent at $910 \mathrm{MHz}$ the current density is high in the Hilbert element which is responsible for the low frequency resonance. At $1912 \mathrm{MHz}$ the current density is high in both the polygonal and the Hilbert elements.

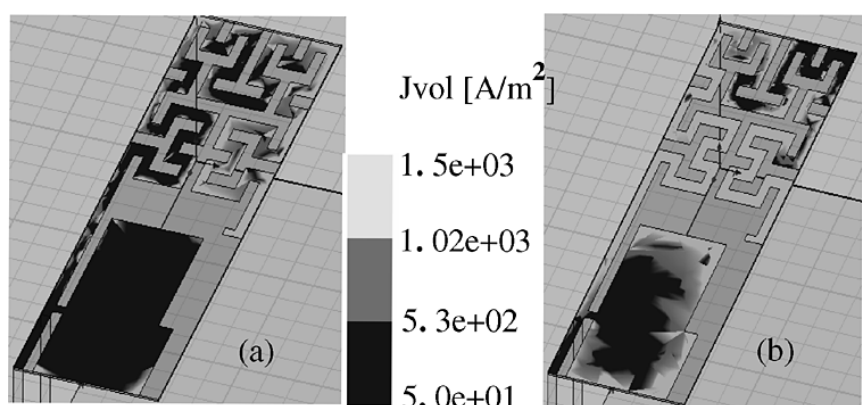

Fig. 6. Computed current distributions for Antenna C (a) at $910 \mathrm{MHz}$ and (b) at $1912 \mathrm{MHz}$.

Computed radiation patterns for antennas $\mathrm{C}$ and $\mathrm{D}$ are shown in Fig. 7. Patterns are computed at 910 and $1912 \mathrm{MHz}$ for antenna $\mathrm{C}$ and 920 and $1925 \mathrm{MHz}$ for antenna D. In all cases, the low resonant frequency pattern at $\phi=0^{\circ}$ shows uniform coverage in the azimuthal plane which is desirable in mobile wireless application with the $\mathrm{E}_{\phi}$ component being dominant. In the elevation plane $\left(\phi=90^{\circ}\right)$ the pattern resembles that of a dipole antenna with some cross-polarization (suppressed below $20 \mathrm{~dB}$ ). Similarly, the azimuthal pattern in the high frequency band is also fairly uniform with both components being close to each other. In the elevation plane the pattern has a butterfly shape. The peak gain at $910 \mathrm{MHz}$ is $2.4 \mathrm{dBi}$ and at $1912 \mathrm{MHz}$ it is $4.6 \mathrm{dBi}$. A longer antenna and ground plane at the high frequency results in a more directive pattern and, hence, the high gain. It is well known that current on the tip of monopole is zero, which results in zero fields along $\theta=0^{\circ}$. But the proposed PIFA has nonzero fields along $\theta=0^{\circ}$ providing better coverage in the upper hemisphere as compared to vertical monopole antenna.

\section{CONCLUSION}

A miniaturized Hilbert type PIFA comprising of a Hilbert and a plate-type element is proposed. This geometry occupies only 

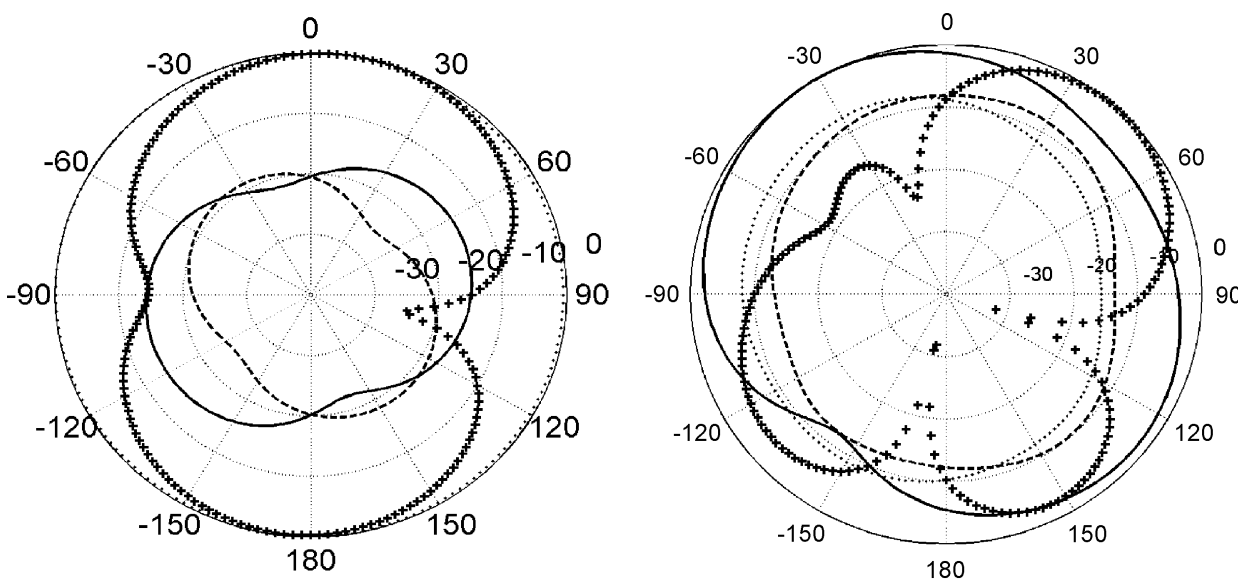

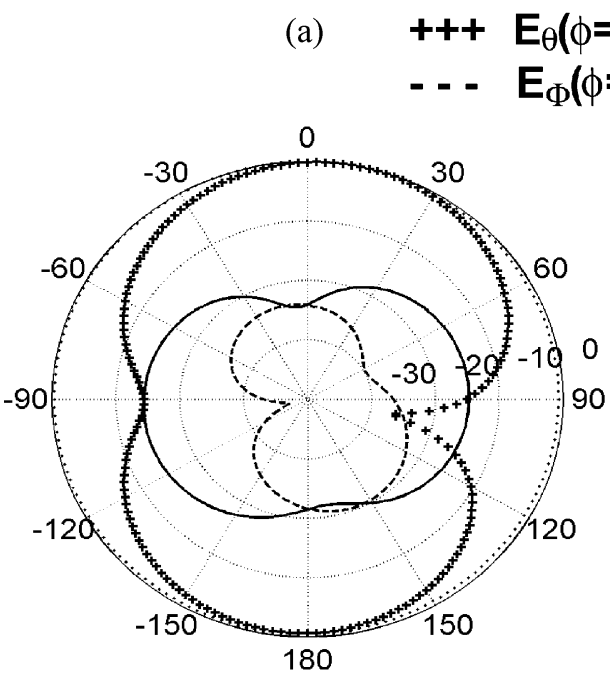

(c) (b) $-\mathbf{E}_{\theta}(\phi=0)$

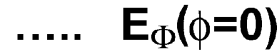

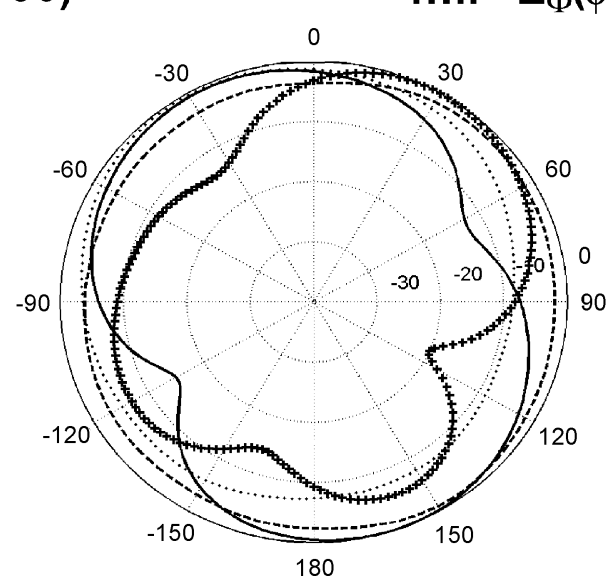

(d)

Fig. 7. Computed radiation patterns for antenna C at (a) $910 \mathrm{MHz}$ and (b) $1912 \mathrm{MHz}$; antenna D at (c) $920 \mathrm{MHz}$ and (d) $1925 \mathrm{MHz}$.

about $50 \%$ of the volume (only $4.3 \mathrm{~cm}^{3}$ ) needed by a conventional metal plate-type PIFA. Computed and measured bandwidth of the antenna indicates good performance for dual-band mobile phone application at around 900 and $1900 \mathrm{MHz}$.

\section{REFERENCES}

[1] M. A. Jensen and Y. Rahmat-Samii, "Performance analysis of antennas for hand-held transceivers using FDTD," IEEE Trans. Antennas Propag., vol. 42, no. 8, pp. 1106-1113, Aug. 1994.

[2] L. Z. Dong, P. S. Hall, and D. Wake, "Dual-frequency planar inverted-F antennas," IEEE Trans. Antennas Propag., vol. 45, no. 10, pp. 1451-1458, Oct. 1997.

[3] M. Ali, R. A. Sadler, and G. J. Hayes, "A uniquely packaged internal inverted-F antenna for bluetooth or wireless LAN application," IEEE Antennas Wireless Propag. Lett., vol. 1, no. 1, pp. 5-7, 2002.
[4] M. Ali and G. J. Hayes, "A small printed integrated inverted-F antenna for bluetooth application," Microwave Opt. Technol. Lett., vol. 33, no. 5, pp. 347-349, Jun. 5, 2002.

[5] M. F. Abedin and M. Ali, "Modifying the ground plane and its effect on planar inverted-F antennas (PIFA's) for mobile phone handsets," IEEE Antennas Wireless Propag. Lett., vol. 2, no. 15, pp. 226-229, 2003.

[6] M. Ali, G. J. Hayes, H.-S. Hwang, and R. A. Sadler, "Design of a multiband internal antenna for third generation mobile phone handsets," IEEE Trans. Antennas Propag., vol. 51, no. 7, pp. 1452-1461, Jul. 2003.

[7] S. R. Best and J. D. Morrow, "The effectiveness of space-filling fractal geometry in lowering resonant frequency," IEEE Antennas Wireless Propag. Lett, vol. 1, pp. 112-115, 2002.

[8] J. Zhu, A. Hoorfar, and N. Engheta, "Bandwidth, cross-polarization and feed point characteristics of matched Hilbert antennas," IEEE Antennas Wireless Propag. Lett, vol. 2, pp. 2-5, 2003.

[9] X. Chen, S. S. Naeini, and Y. Liu, "A down sized printed Hilbert antenna for UHF band," in Proc. IEEE Antennas and Propagation Society Int. Symp., vol. 2, Columbus, OH, 2003, pp. 581-584. 